\title{
Communication of a Natural Disaster. An Earthquake Case in Social Media and Online Newspapers
}

\author{
Andrea Volterrania, Domenica Fioredistella Iezzia ${ }^{a}$, Alessio Ceccherellia
}

\begin{abstract}
In history, every media development has contributed to a change in human beings' perception of reality and in the way we have acted in that reality. Orality, literacy, the printing press, and electricity have done it, and so is digital and social media. Reticularity, horizontalization, distributed and informal learning are some of the keywords of this era. The change in perception of natural disaster management through social media (Twitter) both in real time and in the following months is at the centre of the reflection of the work. To study the opinions of Italians regarding the natural disaster of Central Italy in 2016, the authors scraped Italian language Tweets from the web on the subject of earthquakes. They collected all of the Tweets containing the hashtag "terremoto" for nine months (from August 2016 to May 2017). Data analytics was performed with Twitter of R statistics and has resulted in a large corpus to which the authors have applied multivariate techniques in order to identify the contents and the sentiments behind the shared comments. The results show how social media relations and perception change are complex and articulated and can be one of the ways to improve communication activities for prevention.
\end{abstract}

\section{Keywords}

Digital, social media, natural disaster, perception

A natural disaster is a break in the daily lives of people who sometimes are not expecting it (earthquakes), sometimes with a short or medium notice period (floods, tsunamis, and volcanic eruptions).

When a natural disaster is activated, a "totalizing" communicative process is also activated for the people involved. Individual and collective perception is strongly stressed both from an emotional point of view and from a relational and social point of view. It is, in fact, a communicative flood that goes well beyond any media experience that each of us can experience in contemporary society. It is simultaneously a symbolic and value breaking of reality and of the individual and collective imagination, that inevitably leads to a sudden transformation of perception.

Perception is the first phase of the communication model for prevention proposed by Volterrani (Volterrani 2017) from which to start the authors' analysis.

aUniversity of Rome Tor Vergata, Italy

\section{Correspondent Author:}

Andrea Volterrani, Department of Enterprise Engineering, University of Rome Tor Vergata, Via Columbia 200137 Rome, Italy 


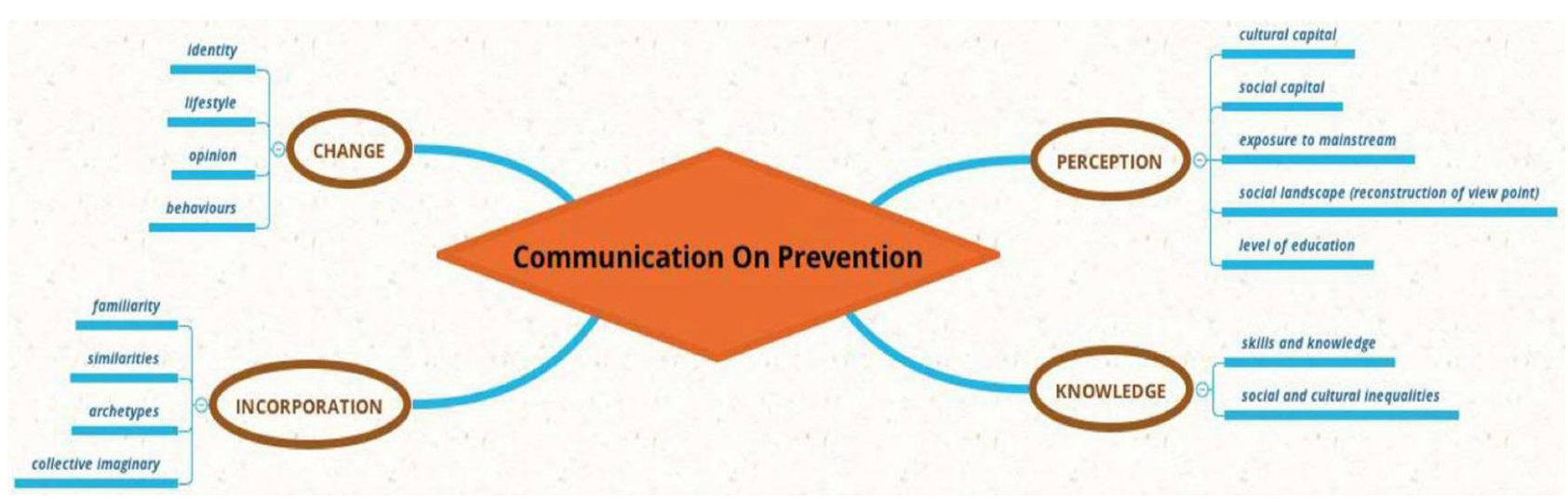

Figure 1. A Model for Communication on Prevention.

The model provides four distinct phases: (1) the perception, selection, and relevance of the topic or issue; (2) knowledge of the topic or issue; (3) the incorporation of the issue or problem; and (4) the possible change of attitudes and behaviour in relation to the issue or problem (see Figure 1). In communication for prevention, change of perception is the first step necessary to initiate a communicative process that can contribute to a change of ideas and behaviour. When the natural disaster occurs, the change in people's perception is immediate. Sometimes the change had already happened thanks to participation in prevention activities.

The second step the authors want to emphasize instead concerns what happens in the immediate aftermath of the disastrous event in the following months. From the sudden change of perception, it slowly moves to a change management phase where new skills and new knowledge are needed to adapt and react both as individuals and as a community. It is certainly the time when individual resilience and communities emerge in strength ${ }^{1}$ (Norris et al. 2008; Volterrani 2016), namely the ability to react to adverse events. At this stage, the second phase of the communicative process for prevention, knowledge, prevails. This is a delicate stage because the cognitive insights (and the skills to be acquired) range from the days after the incident (where to sleep, where to eat, and how to resume work) to the next few months (how to find resources to continue working, how to try to recover personal belongings, memories, but also the most important objects of everyday life, how to start reconstruction or whether to decide to change communities). It is no longer instantaneous communication, but it resembles much more than what can be defined as public utility: simple, but complete, with a comprehensible but in-depth and certain language, a communication for returning knowledge, trust and reconstructing links from affected communities. A communication from the bottom but connected and linked to institutions (Peruzzi and Volterrani 2016) to allow maximum involvement of the people involved in the natural disaster.

The authors' analytical work has sought to understand the role of social media (especially Twitter) and the mainstream media (the four most popular newspapers in Italy) in the first two phases of the communicative process, perception and knowledge, from August 24, 2016 to August 24, 2017.

\section{DATA AND METHODS}

The authors built two corpora using traditional and new media: 
(1) For the traditional media: the authors collected all the articles published by three newspapers from their online versions (no. 150): La Repubblica, Il Corriere della Sera, and ANSA, from August 24, 2016 to September 24, 2016-four weeks;

(2) For the new media: the authors scraped Italian language Tweets from the web on the subject of the earthquake. They collected all the messages in Italian language containing the expression "terremoto centro Italia 2016" (about 8,000) from August 24, 2016 to August 24, 2017.

For the corpora, the authors performed the analysis using IRaMuTeQ ${ }^{2}$ (Ratinaud 2009), with a sequential process: (1) pre-processing composed of tokenization, lemmatization, stop-words removal (prepositions, articles, and conjunctions), removing of words with frequency lower than 10; (2) lexicographic analysis with quantitative description of the corpora; (3) specificity and correspondence analysis (Lebart, Salem, and Berry 1998) for the first corpus on a lexical table that is of size (types $\mathrm{x}$ newspapers), and for the second corpus (types x Twitter); (4) clustering: the authors classified the contents, with an iterative process where the descending hierarchical classification method decomposes the classes until a predetermined number of iterations fails to result in further divisions. The result is a hierarchy of classes, which may be schematized as a dendrogram (Reinert 1987; 1990); and (5) the Fruchterman-Reingold Algorithm accomplishes a similarity analysis, so it is possible to see the different lexical worlds (Marchand and Ratinaud 2012). In the graph of each cluster, in the network, the vertices (the specific forms) joined by segments called edges, which can have different text size (Baril and Garnier 2015). The vertex text size is proportional to frequency and the edge width is proportional to score (co-occurrence).

\section{MAIN RESULTS}

For the newspaper corpus, the authors detected four clusters (see Figure 2): the disaster (purple class) and the storytelling (red class) drive communication in newspapers. Information and specific stories (about towns and citizens) occupy the main parts of journalistic chronicles. The chronicle of the days after (heavenly cluster) and the point of view of official science (green cluster) work together, and more or less at the same time. From one side, the basis of individual and symbolic stories begins to be told. From the other, a deepening scientific evaluation tries to provide a technical explanation to the disaster: "Could it have been predicted?", "could anything have been done to prevent the disaster?".

There is no real diversification in the things to be told and the information to be given. Terms regarding the event are similar, in a way sometimes scientific, sometimes informative.

Cluster 4 (the event/purple) is very clear on what happened, but not so detailed: some real places and some information about the event (magnitude, epicentre, shock, tremor, warning, and depth). Cluster 2 (the days after/green) inserts technical and specific details (seismic event, seismologist, sequence, and danger) and cluster 3 (science/heavenly) inserts other technical terms (fault, explain, and generate). In both cases, some gems of reaction appear (observe, future, activation, love, and captivate). When the disaster has been "absorbed" by the population and the media, the individual stories take over and arouse particular emotions (cluster 1/red). The authors can read words related to roles (the mayor), symbolic places (church, cathedral, school, and church tower), specific towns, and emotions (knees, heart, wounded, dead, destroy, and devastation).

Figure 3 shows that the closest classes are heavenly and green, but they are also those with fewest words, $19.1 \%$ and $16.2 \%$ respectively. In terms of number of occurrences, the purple class is the largest one (36.2\%), and the red class (29.5\%) follows.

For the Twitter corpus, the authors detected four clusters (see Figure 4): (1) event/emergency (purple 


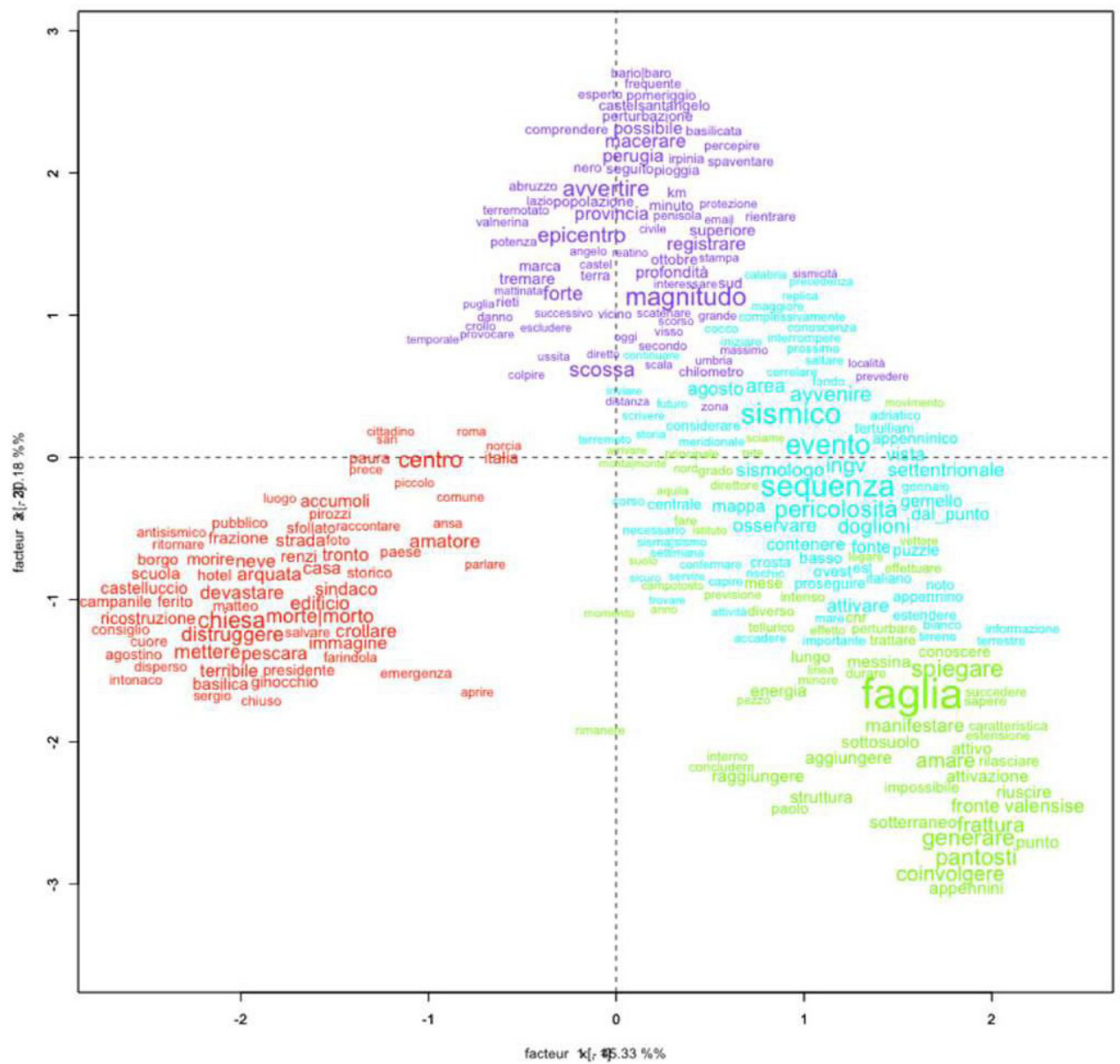

Figure 2. First Factorial Plan. Axes 1 and 2 on Lexical Correspondence Analysis on Actives Forms (Newspaper).

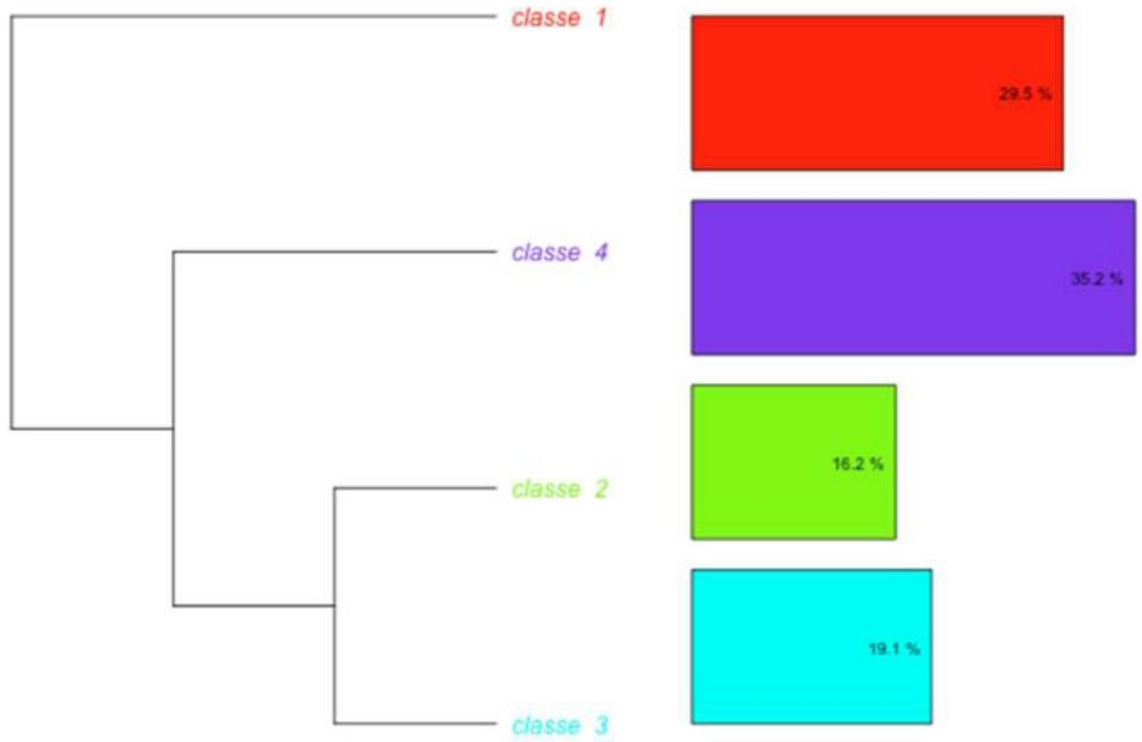

Figure 3. Dendrogram of the Newspaper Corpus. 


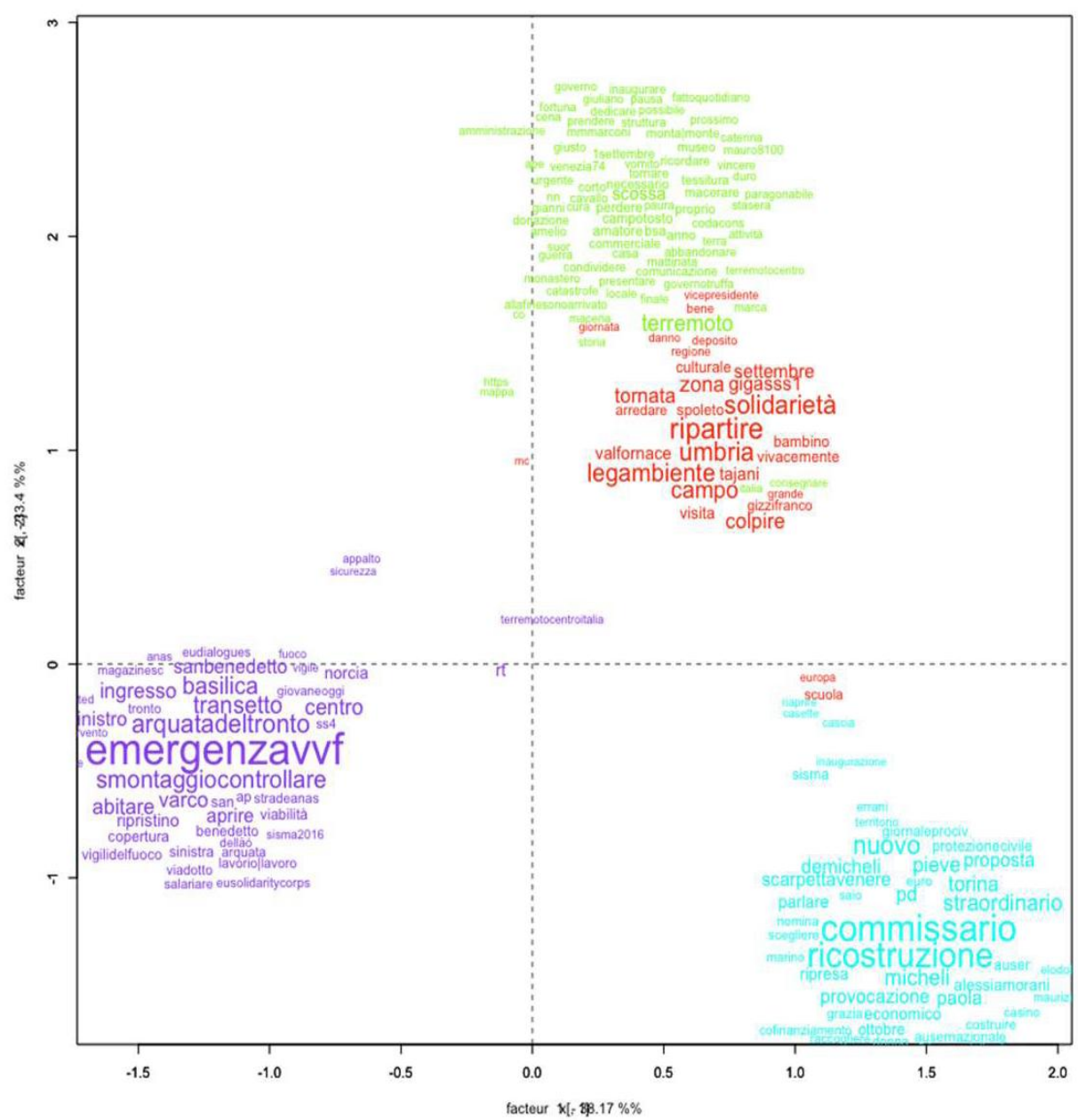

Figure 4. First Factorial Plan. Axes 1 and 2 on Lexical Correspondence Analysis on Actives Forms (Twitter).

class): in this group, people talk about the time of the event/natural disaster. The communication revolves around two themes: the disaster and the first rescue efforts; (2) emotion (green cluster) in this group, immediately after the natural disaster, the strong emotions connected to the natural catastrophe explode; (3) solidarity (red class): in this group, the authors collected NGO interventions and solidarity which are the third time of communication. They can read the community's reaction and support of the earthquake victims; and (4) reconstruction (heavenly cluster): in this group, the community speaks about the last space of the reconstruction and the problems/opportunities associated with the role of public institutions.
Figure 5 shows that the closest classes are red (intervention by the NGOs and individuals) and green (emotions). They are also small clusters: the red and green ones count, respectively, $11.6 \%$ and $26.2 \%$ of the types. In terms of number of occurrences, the purple class is the largest one (37.6\%).

The graph of the cluster event/emergency describes the actions that are accomplished after the first earthquake shakes housing and basilica, the arrival of firemen, and contracts awarded to various firms for reconstruction (see Figure 6). The graph has a star structure where the keyword used for research "earthquake in the centre of Italy" appears in the centre. 


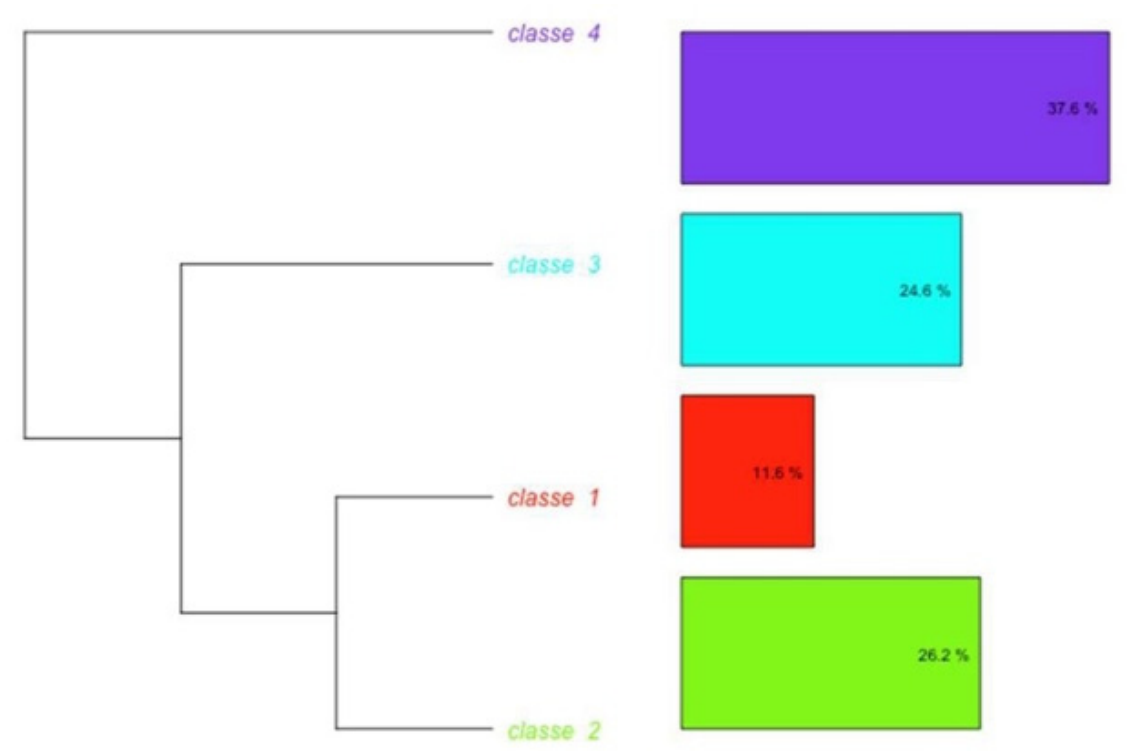

Figure 5. A Dendrogram of the Twitter Corpus.

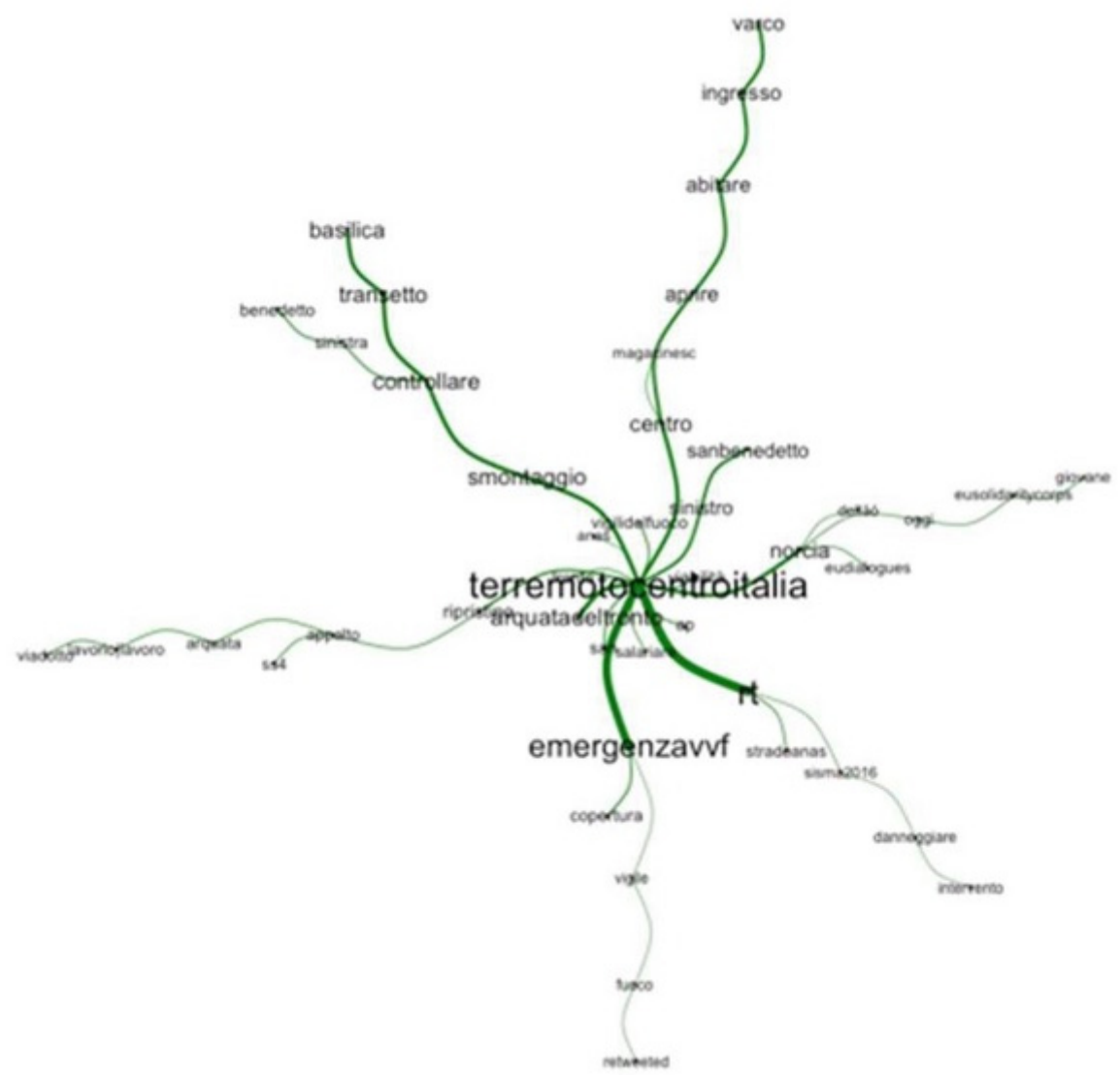

Figure 6. Fruchterman-Reingold Graph of the Cluster Event/Emergency. 


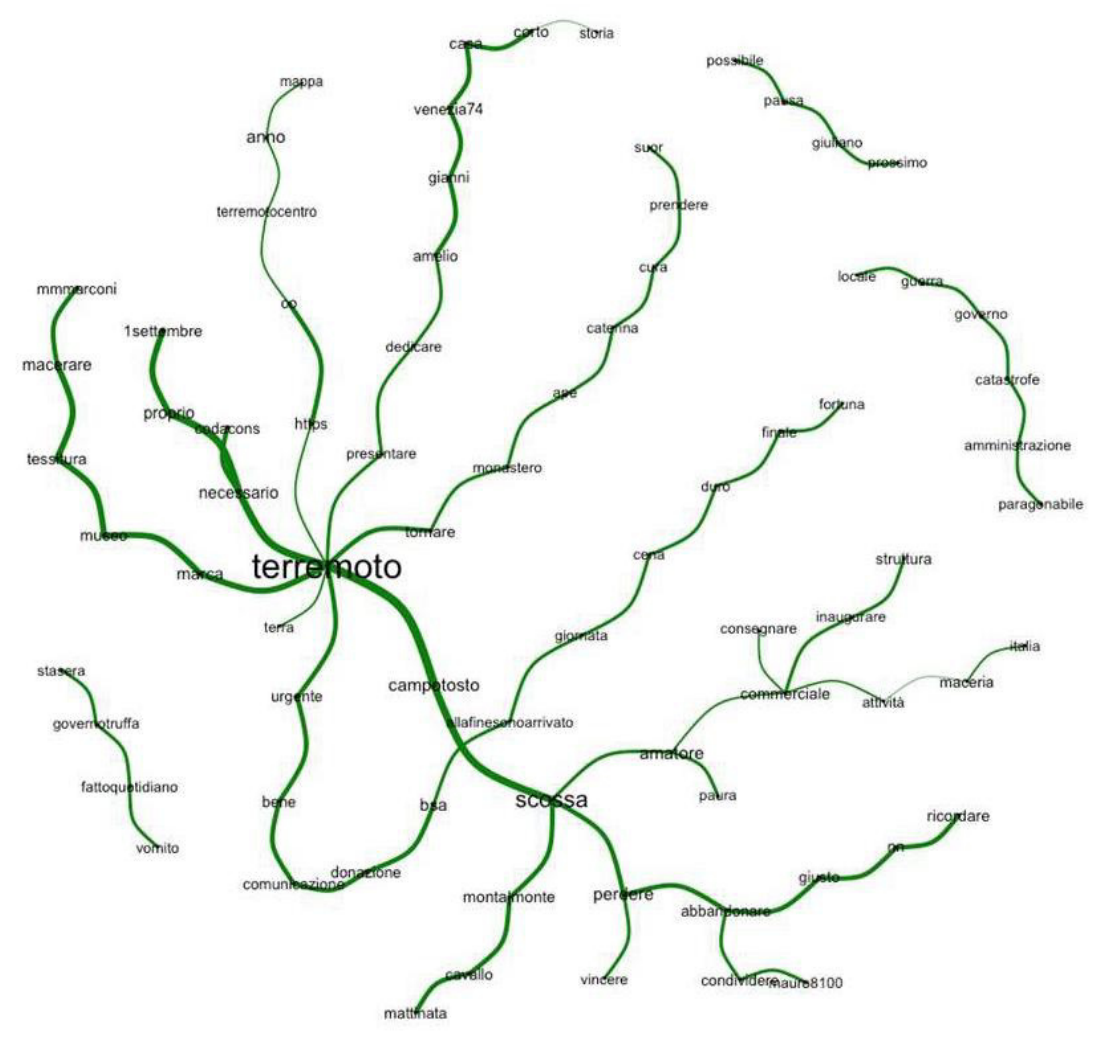

Figure 7. Fruchterman-Reingold Graph of the Cluster Emotions.

Figure 7 shows not only the feelings of the individuals involved in the catastrophe, but also the actions taken. In this graph, both the feelings of the individuals involved in the catastrophe show their actions. Also, this graph is not connected, and there are unsubscribed links between them, e.g. the sub-graph which points out extremely negative thoughts about the government.

For this class, Figure 8 underlines a complete graph where the most important words are "solidarity", "environment", and "zone".

Figure 9 once again shows the presence of a complete graph. In the node in the centre, in the bridge position, is the word "commissioner". "Reconstruction", "structures", "funds", and "stakeholders involved", are the links that connect them all.

It can make some observations about these graphs, both for form and for the content. Regarding the form, the configuration of relations among the semantic nodes shows that:

The event and the rebuilding have a centre of communication: all communications seem to emanate/irradiate from a central point. The semantic representation of the event is incredible: it is just like the shake.

Solidarity is more jagged: there are at least two centres of aggregation, maybe related to different visions of solidarity.

Emotions act with no specific rules: there is not a real centre but the word that indicates the event ("earthquake"). The rest explodes in a web.

Regarding the content, the reaction of the population during and after a crisis shows that:

Social media (in the authors' case, Twitter) can help highlight and share emergency situations with particular clarity (topics, locations, and specific issues) and speed. 


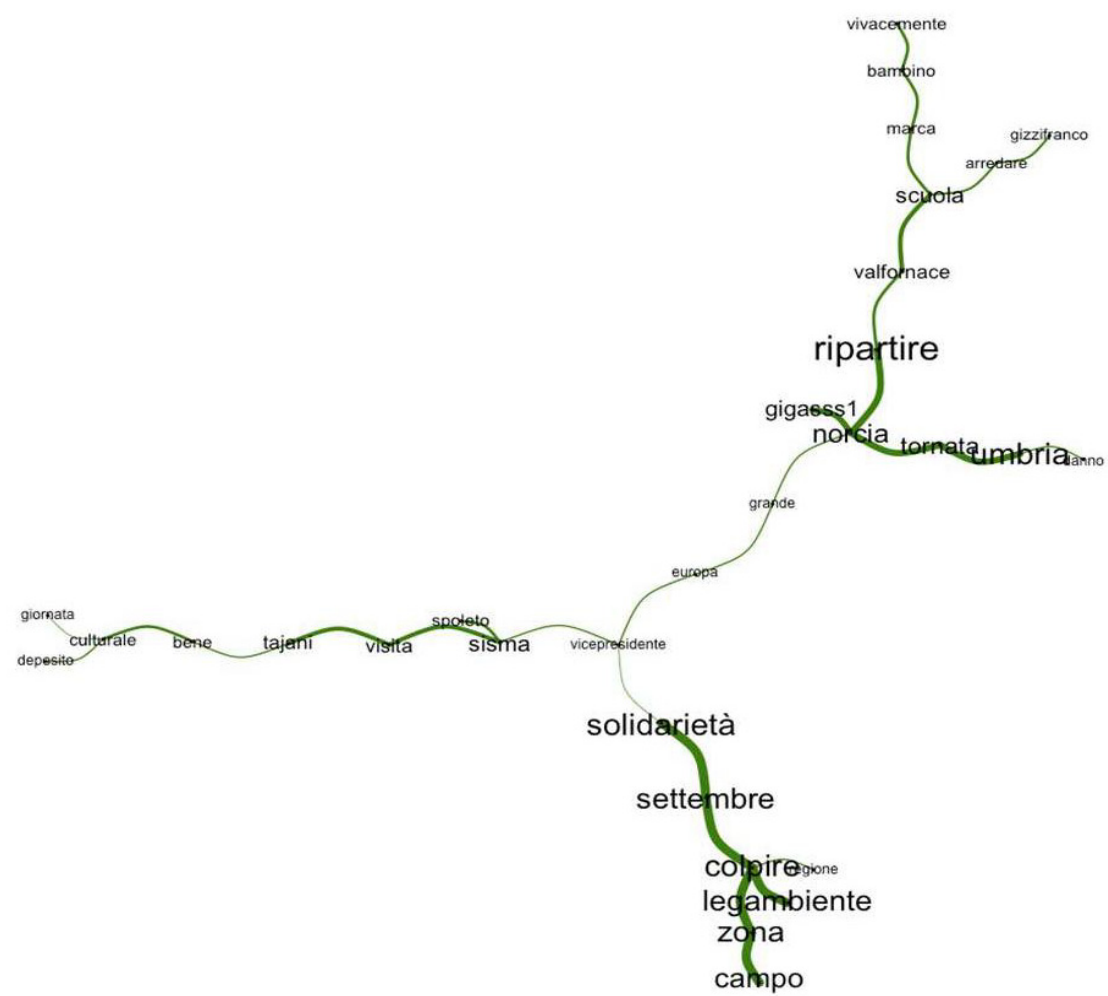

Figure 8. Fruchterman-Reingold Graph of the Cluster Solidarity. Intervention by the NGOs and Individuals.

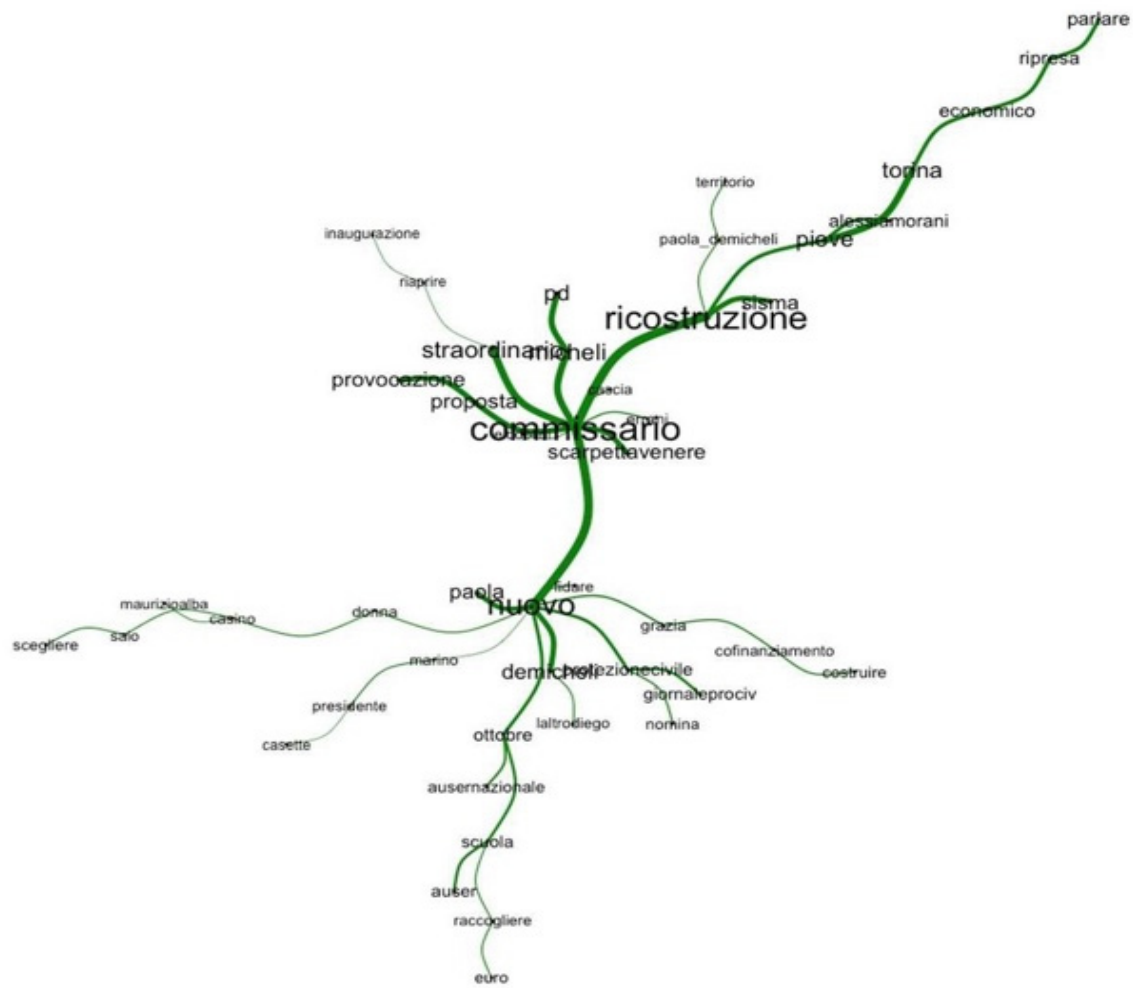

Figure 9. Fruchterman-Reingold Graph of the Cluster Reconstruction. Intervention by the Institutions. 
At the same time, social media lets strong emotions be shared on the continuing natural disaster, but does not become sedentary heritage of communities.

Solidarity is indeed important but not so much on social media. Tweets find less space in favour of silent actions in the territory of volunteers and citizens.

Social media plays again a role for denouncing or promoting actions related to reconstruction.

\section{CONCLUSIONS}

The results show how social media relations and perception change are complex and articulated, and can be one of the ways to improve communication activities for prevention. The model of communication for prevention that the authors have illustrated at the beginning focuses attention on two aspects that can be detected by the results of their analysis. The first aspect is perception. Both traditional online media and social media play an important role. Traditional online media is concerned with the visibility of the natural disaster when it happens to try to occupy space in the collective imagination. Exceptionality, emotionality, heroism, suffering, pain, and tragedy emerge. All aspects that are part of the usual toolbox of journalism, but which do not allow change in the collective perception in the moment of the disaster. Sometimes they can provide misleading indications that destabilize the perception both of the population directly involved and of the population outside the natural disaster. An example is related to the request for blood donations immediately after a natural disaster, a fact that completely ignores the system of blood donations that provides compensation precisely on these occasions between different regions of Italy. Social media, with respect to perception, is much more tied to giving space on one side to emotions coming from the bottom, and on the other side to service information. If the activation of individuals is normal in the first case, on the other hand, preventive communication actions are lacking in preventative terms that can help manage the proposed emotional load responsibly. In the second case, instead, the service information produced from the bottom can represent, if well coordinated, verified, and managed (to select fake news), an important resource for the first interventions of the civil protection system.

The second important aspect is knowledge. On this, neither the traditional online media system nor social media work to increase the knowledge available to citizens, especially during the reconstruction phase. The void is particularly evident on two issues: (1) the silence on what happens immediately after and in the months after the natural disaster, because it no longer has the features of news or the emotionality necessary to make news; and (2) the inability to promote "operational knowledge" for the citizens involved and "knowledge of solidarity" in the citizens not involved. In part, this can be linked to the specific characteristics of the media, but it is true that the lack of an ethics of responsibility and professionalism plays an important role (Silverstone 2006).

In conclusion, the results of the research show that in the context of prevention and reconstruction, the role of traditional media and social media is still not present. A greater link between media professionals and the civil protection system could be the path to follow to develop communication for prevention and reconstruction after a natural disaster.

\section{Notes}

1. For a closer look, see the results of the European project INDRIX, http://indrix.samaritan-international.eu.

2. IRaMuTeQ is an open software, distributed under license GNU GPL, based on R statistical software and on Python language.

\section{References}

Baril, E. and B. Garnier. 2015. IRaMuTeQ 0.7 alpha 2 
Interface de $R$ pour les Analyses Multidimensionnelles de Textes et de Questionnaires (IRaMuTeQ 0.7 alpha $2 R$ Interface for Multidimensional Text and Questionnaire Analysis). Retrieved (http://www.iramuteq.org/document ation/fichiers/Pas\%20a\%20Pas\%20IRAMUTEQ_0.7alpha2 .pdf).

Cameron, D. 2001. Working With Spoken Discourse. London: SAGE.

Coates, J. 2007. "Talk in a Play Frame: More on Laughter and Intimacy.” Journal of Pragmatics 39:29-49.

Drew, P. and J. Heritage. 1992. "Analysing Talk at Work: An Introduction.” Pp. 3-65 in Talk at Work, edited by P. Drew and J. Heritage. Cambridge: Cambridge University Press.

Lebart, L., A. Salem, and E. Berry. 1998. Exploring Textual Data. Dordrecht: Kluwer Academic Publishers.

Marchand, P. and P. Ratinaud. 2012. "L'analyse de similitude appliquée aux corpus textuels: les primaires socialistes pour l'élection présidentielle française" (The Similarity Analysis Applied to Textual Corpora: The Socialist Primaries for the French Presidential Election). Actes des 11eme Journées internationales d'Analyse statistique des Données Textuelles (JADT) 2012:687-699.

Norris, F. H., S. P. Stevens, B. Pfefferbaum, K. F. Wyche, and R. L. Pfefferbaum. 2008. "Community Resilience as a Metaphor, Theory, Set of Capacities and Strategy for Disaster Readiness." American Journal of Community Psychology 41:127-150.

Peruzzi, G. and A. Volterrani. 2016. La comunicazione sociale (The Social Communication). Roma-Bari: Laterza.

Ratinaud, P. 2009. IRaMuTeQ: Interface de $R$ pour les Analyses Multidimensionnelles de Textes et de Questionnaires (IRaMuTeQ: $R$ Interface for Multidimensional Text and Questionnaire Analysis). Retrieved (http://www.iramuteq.org).

Reinert, M. 1987. "Classification descendante hiérarchique et analyse lexicale par contexte: application au corpus des poésies d'Arthur Rimbaud" (Hierarchical Top-Down Classification and Lexical Analysis by Context: Application to the Corpus of Arthur Rimbaud's Poems). Bulletin de Méthodologie Sociologique 13:53-90.

1990. “ALCESTE. Une méthodologie d'analyse des données textuelles et une application: Aurelia de Gerard de Nerval" (ALCESTE. A Methodology for Analysing Textual Data and an Application: Aurelia de Gerard de Nerval). Bulletin de Méthodologie Sociologique 26:24-54.

Silverstone, R. 2006. Media and Morality. On the Rise of the Mediapolis. London: Polity.

Volterrani, A. 2016. "How to Build Prevention for the Elderly and Disabled Before Natural Disasters? The Added Social Value of Voluntary Organizations in Europe." Sociology and Anthropology 4(2):92-98.

- 2017. "From Perception to Change. A Model for Prevention Communication." Proceedings of the 3rd World Conference on Media and Mass Communication 2:82-90.

\section{Bios}

Andrea Volterrani, Ph.D., professor and researcher, Department of Enterprise Engineering, University of Rome Tor Vergata, Italy; research fields: nonprofit organizations communication, participation, social media, social resilience, community development.

Domenica Fioredistella Iezzi, Ph.D., associate professor, Department of Enterprise Engineering, University of Rome Tor Vergata, Italy; research fields: social statistics, social resilience, social media, big data.

Alessio Ceccherelli, Ph.D., research grant in Educational Technologies, Scuola Istruzione a Distanza, University of Rome Tor Vergata, Italy; research fields: media education, educational technologies, storytelling and communication, media studies, game based learning. 